\title{
COMPARACIONES, SÍMBOLOS Y PREFIGURACIONES: EL MUNDO FÍSICO Y SU PROYECCIÓN MORAL Y RELIGIOSA
}

\author{
JOSÉ-LUIS MARTÍN \\ Universidad Nacional de \\ Educación a Distancia \\ (Madrid)
}

\section{SUMARIO}

1. Virtudes y vicios: "modelos" y representación.- 2. Los dones del Espíritu y sus equivalencias.- 3. El hombre y sus mundos.- 4. El mundo físico y Dios; los santos y su prefiguración.

De la Historia Natural escrita por el franciscano Juan Gil de Zamora en los años finales del siglo XIII ${ }^{1}$ sólo se ha conservado la parte inicial: el libro primero correspondiente a la letra $\mathrm{A}^{2}$ y el prólogo de la $\mathrm{B}$, pero son tantas las disgresiones, añadidos y ampliaciones que introduce el autor que es posible encontrar noticia detallada sobre palabras tan alejadas de la A

\footnotetext{
'IOHANNES AEgidius Zamorensis (Juan Gil de Zamora). Historia Naturalis. Estudio y edición Avelino Domínguez García y Luis García BALLESTER, 3 volúmenes, Valladolid

Sobre Juan Gil puede verse el trabajo de José-Luis MARTín y Jenaro COSTAS, Juan Gil de Zamora, De preconiis Hispanie o Educación del Príncipe, Zamora 1997.

También el Tratado de los Animales -ocupa las pp. 1558-1799 de la edición- acaba en la letra A de araña.

"Anuario de Estudios Medievales". 27 (1997)
} 1994. 
como Veneno o Ydropesía ${ }^{3}$, y una sola letra de su enciclopedia nos permitirá acercarnos prácticamente a todo el saber medieval, a las preocupaciones de los hombres del siglo XIII y a los remedios que conocen y, suponemos, aplican para curar enfermedades o quemaduras, embellecer la piel, abortar, expulsar las lombrices, dar muerte a los animales venenosos... y contribuir a la salvación del alma, que para esto y para mucho más sirve, por ejemplo, la lechuga llamada de "oreja de asno o de mulo"4 cuyas propiedades físicas permiten a Juan Gil recordar que del mismo modo que la lechuga excoria la piel, el avaro despoja al prójimo; y así como el jugo de la lechuga masticada con calma da muerte a los animales venenosos, "una decisión pensada concienzudamente impide las desgracias futuras; porque lo que se puede prever hiere menos y aceptamos más resignadamente los males del mundo, si nos protegemos contra ellos con el escudo de la prudencia".

Juan Gil no es original y su obra es en muchos casos, como ha probado García Ballester, copia literal de las enciclopedias del saber recopiladas por Bartolomé Ánglico, Tomás de Cantimpré, Vicente de Beauvais o Alberto $\mathrm{Magno}^{5}$, pero este carácter no quita sino que añade interés a la obra de Juan Gil, recolector diligente de cuanto se conocía o creía en los años finales del siglo XIII, y, como sus predecesores y contemporáneos, convencido del paralelismo existente entre el mundo físico, el moral y el religioso. Interesa conocer el mundo, pero interesa sobre todo extraer las enseñanzas morales que de él se desprenden, hablar de las propiedades de las cosas naturales, y de las "que se desprenden de las cosas naturales", y recordar que se busca el conocimiento del mundo físico "con

\footnotetext{
${ }^{3} \mathrm{Al}$ hablar de los animales, por ejemplo, se detiene en el estudio de sus miembros, alimentación, sangre, esperma, orina...

${ }^{4 " C u a n d o ~ s e ~ r o c i ́ a ~ c o n ~ v i n a g r e ~ e s ~ b u e n a ~ p a r a ~ l a ~ m o r f e a . ~ E x c o r i a ~ l a ~ p i e l . . . . ~ C o n ~ h a r i n a ~ d e ~}$ cebada elimina la erisipela... Hace desaparecer las escrófulas cuando se la aplica con sebo. Se pone con cera sobre todo tipo de úlceras y principalmente sobre las quemaduras con fuego. La raíz... asienta el estómago y su cocción con agua de... cártamo... es eficaz para el dolor del bazo y para la ictericia...., para el dolor de riñones o para la piedra en los mismos. Cuando una mujer se aplica por bajo su raíz, aborta. Sus hojas, cocidas en vino, estriñen el vientre... Resuelve los humores coléricos. Y la raíz de la variedad que tiene las hojas cetrinas, con hisopo y mostaza, mata las lombrices y las saca fuera... La cocción de raíz... es buena para las fiebres rebeldes. Cuando se mastica un poco de la variedad cetrina... y se arroja sobre los animales venenosos, los mata. Las otras dos variedades son buenas para las mordeduras de serpiente, tanto bebidas como untadas o escupidas", según indica Avicena (I, p. 133).

${ }^{5} \mathrm{Ob}$. cit., vol. I, pp. 55 y siguientes.
} 
el fin de disponer de un medio más adecuado para conocer y amar más al creador"6.

Como cabía esperar en un franciscano del siglo XIII, el comienzo de la sabiduría es Dios; a Él y a la Virgen hay que referir cuanto se conoce, a Él debe agradecerse el conocimiento 7 y entre los libros "científicos" han de incluirse en primer lugar los libros sagrados como hace Juan Gil en el prólogo al Tratado sobre los animales: "Cuando empecé a indagar y conocer las características y modos de actuar de todos los animales..., al punto me acordé de aquellas palabras del capítulo primero del Génesis, que dicen que Dios supremo y eterno creó de la tierra tres tipos de animales...; los domésticos los creó para que prestaran ayuda al hombre...; los reptiles y los animales salvajes los creó para poner a prueba al hombre pecador". Pero, hecha esta obligada salvedad, quien aspire al conocimiento del mundo natural debe recurrir "a los dichos de Aristóteles, Avicena, Plinio, Jorath, Isidoro y otros filósofos y santos" $^{18}$ y a los escritos, podríamos añadir, de su intérprete Juan Gil, plenamente convencido del valor científico de su obra a pesar de las críticas que, sin duda, no le ahorraron sus contemporáneos: "Han de saber no obstante todos los detractores de la verdad que, teniendo esta obra a mano, cualquiera puede acceder en poco tiempo a los conocimientos básicos y verídicos de todas las ciencias... Sepan no obstante mis detractores, quienes no saben otra cosa que proferir ladridos contra las personas que trabajan de verdad, que hasta el día de hoy no se ha escrito nada tan completo y acabado sobre la naturaleza y propiedades de los animales... como lo que, con la ayuda de Dios, se va a tratar en esta obra sin prejuicio de ningún tipo..." ${ }^{9}$ para conocer la realidad física y extraer las

${ }^{6} \mathrm{Pp} .1551$ y 1559.

${ }^{7} \mathrm{El}$ libro dedicado a la letra A finaliza con una acción de gracias "a Aquél que es principio y fin de todo bien... (y) a la divina Madre del Rey Jesús, por cuya intercesión y ayuda hemos alcanzado los caudalosos ríos de las gracias comunes..." (p. 1551), y el prólogo del libro segundo no es sino una petición a "Dios eterno, bien supremo, luz del mundo... concédeme la luz para poder verte..., sabiduría para entenderte, perdona mis pecados para alcanzar tu misericordia...; pon tu mano sobre mi boca, conviértela en espada afilada y haz de mi lengua una flecha elegida para proclamar las maravillas de tus creaturas, cuyo nombre comienza por la letra B" (p. 1553).

${ }^{8}$ P. 1559.

${ }^{9} \mathrm{Pp} .1557$ y $1559-1561$. El texto recuerda las palabras de Juan Gil contra quienes acusan al concejo zamorano: "Escuchen, por tanto, los detractores y los que ladran contra el concejo numantino y sepan que no hemos leído que haya hombres que por la fidelidad hayan soportado lo más duro y difícil del mundo, igual que los Zamoranos..." (De preconiis Hispanie, p. 167). 
enseñanzas morales correspondientes, aunque no siempre se expliciten o incluyan las "consideraciones morales porque", como señala al hablar de la alheña, "son evidentes a los ojos de las personas inteligentes..." y porque si se incluyeran en todos los casos, "si pretendiera tratar en detalle todos los temas, aburriría con toda seguridad a los expertos y entendidos y esta obra se prolongaría demasiado" 10 .

Como en el caso de la lechuga de oreja de mulo, las virtudes y propiedades físicas de la mandrágora, del abrótano o de la piedra absicto tienen también su correspondiente utilización moral: lo mismo que la mandrágora "embriaga y priva al hombre del sentido corporal, así los placeres carnales privan al hombre del sentido espiritual" ${ }^{\prime \prime} ;$ y así como el abrótano hace crecer el pelo de la barba y de la cabeza, y detiene la hemorragia de las encías, "el buen juicio del hombre bueno hace nacer los buenos pensamientos de la mente... (y) ataja el flujo de los malos pensamientos"12; el absicto sirve para llamar la atención sobre el alma con la que tiene una fuerte similitud: la piedra es negra y pesada, y pesada y negra es el alma viciosa; tiene el absicto unas venas o rayitas rojas, que pueden verse en el alma cuando se arrepiente; la piedra retiene el calor durante cuatro o siete días, y el alma tocada por el fuego del Espíritu Santo guarda el amor de Cristo "durante las cuatro estaciones del año o durante los siete días que dura la vida humana"13, y las comparaciones pueden extenderse al campo de labor, rico en frutos como el alma virtuosa, o parecido al alma viciosa cuando está encharcado ${ }^{14}$. A la garza real se parece el alma contemplativa:

\footnotetext{
${ }^{10} \mathrm{P} .301,0$, como señala en las páginas dedicadas a la alopecia: "lo dicho sugiere muchas lecciones morales. Por eso es suficiente indicar el camino en algunas cuestiones, no en todas, con el fin de evitar una extensión excesiva de esta obra" (p. 363). "De lo dicho se desprenden consideraciones morales evidentes", recuerda una vez más al hablar del amidén (p. 379) o del acederaque: "De lo dicho puede el hombre sabio sacar fácilmente tema de reflexión moral" ( $\mathrm{p}$. 1549).

"Es la mandrágora un poderoso anestésico recomendado, por ejemplo, cuando es preciso amputar un miembro: "Si alguien quiere amputarse alguno de sus miembros, que beba tres almucet de mandrágora en vino y le producirá subeth, es decir, cierre violento de los ojos, obturación del cerebro y un sueño profundo y continuo" (pp. 133-135).

${ }^{12}$ Recordemos solamente, por su actualidad, las virtudes "capilares" del abrótano, mencionadas ya por Avicena: "va bien para la calvicie... favorece el nacimiento de la barba tardía, cuando se cuece con determinados aceites, gracias a su virtud aperitiva... Cuando se cuece con aciete, calienta la cabeza y elimina su frigidez..." (p. 137).

${ }^{13}$ Puede verse el texto correspondiente al absicto en la p. 139.

${ }^{14}$ P. 267.
} 
aquélla vuela muy alto para evitar la lluvia y contemplar las cosas elevadas, y el alma se eleva "sobre sí misma para quedar suspendida de Dios..." ${ }^{15}$.

\section{VIRTUDES Y VICIOS: “MODELOS” Y REPRESENTACIÓN}

La alheña antes mencionada simboliza la humildad que cura el orgullo humano y junta lo que ha dispersado la vanidad lo mismo que la planta cura apostemas y consolida los huesos rotos. También cura apostemas el almidón, otro símbolo de la humildad, que cura la soberbia del espíritu ${ }^{16}$, y no menor simbolismo encierra un árbol parecido a la alcaparra llamado adrifugin con el que comparte el poder de ablandar apostemas y aliviar las picaduras de avispa: la humildad alivia y suaviza la jactancia y la arrogancia $^{17}$.

Amargo de sabor es el ajenjo, y de propiedades y efectos dulces, como la penitencia: el primero protege paños y papeles de la corrosión, de los ratones y de los gusanos, y la penitencia libra de las tentaciones del demonio, el mundo y la carne; da el ajenjo buen aspecto corporal al hombre, y embellece el alma la penitencia. Mata el ajenjo las lombrices y gusanos del cuerpo y destruye la penitencia los deseos carnales; espabila la hierba la embriaguez física y elimina la penitencia los placeres de los pecados; fortalece el estómago y devuelve el apetito el ajenjo, y la penitencia hace desear los manjares espirituales. Como cura todo el ajenjo, lava la penitencia todos los pecados: "La penitencia rechaza la avaricia, aborrece la lujuria, ahuyenta el orgullo, fortalece el amor, pisotea la soberbia, pone freno a la lengua, reforma las costumbres, odia la malicia, excluye la envidia. Lo mismo que el ajenjo combate la embriaguez, la oftalmía, la dureza del bazo, la opilación del hígado, los gusanos de las orejas, las tinieblas de los ojos, la ictericia y otras enfermedades"18. Virtudes parecidas a las del ajenjopenitencia tiene el aloe, que simboliza el espíritu de la penitencia y la meditación en la pasión de Cristo: el primero preserva de la corrupción,

\footnotetext{
${ }^{15}$ P. 1019.

${ }^{16}$ P. 381

${ }^{17} \mathrm{P} .237$.

${ }^{18} I d$., pp. 139-147. Entre las muchas propiedades del ajenjo se incluye la de reducir el apetito, aunque ha de tomarse con mucho cuidado porque "sus semillas dañan la boca del estómago".
} 
conforta y depura, y nada hay que "cale tan hondo en el alma del pecador como el recuerdo del pecado... y la meditación frecuente de la amarga pasión de Cristo"19. Efecto de la penitencia es la gracia, comparable a la medicina india llamada Accamarath, cuyas hojas evitan la epilepsia; así como la medicina hace "que el epiléptico no caiga al suelo, así la gracia hace que el pecador no caiga ya más en el pecado"20.

Las múltiples virtudes del vinagre tienen cumplida correlación en la abstinencia: el primero enfría, seca, constipa y rompe, y la segunda "enfría el ardor de la lujuria, seca, el humor de la lujuria, constipa el flujo de la lujuria, rompe los lazos de la lujuria y los enerva"21. No menos poder tiene el arbusto o árbol llamado agnocasto cuyo nombre -cordero casto-indica las virtudes que posee: reprime la líbido como podrá comprobar quien esparza agnocasto sobre la cama, se ponga un fomento sobre los genitales, o quien beba un poco de castoreo cocido en el jugo de agnocasto. Lógicamente, este árbol es símbolo de la abstinencia y la sobriedad que generan castidad "porque el vientre que rebosa comida y bebida afloja las riendas de la líbido"22. Abstinencia y continencia son, por otra parte, comparables a la amatista, que si toca una prenda de vestir, "la prenda se torna resistente al fuego y aunque la pongas al fuego no arde, sino que vuelve más clara y resplandeciente" y las virtudes citadas reprimen "las inclinaciones de la concupiscencia y se oponen al espíritu de fornicación"23.

Con la acedera se puede comparar la virtud de la misericordia, buena la primera "para la aspereza de las úlceras, para el impétigo, para las escrófulas y para las apostemas", mientras la segunda socorre a los enfermos, a los débiles y a los necesitados, "en quienes las úlceras, la aspereza, los impétigos y las escrófulas se producen a causa del hambre y de la miseria". La acedera es buena para la ictericia y para los apostemas,

\footnotetext{
${ }^{19}$ P. 333.

${ }^{20} \mathrm{P} .167$.

${ }^{21} \mathrm{Pp}$. 175-181. Como curiosidad copio la fórmula de fabricación del vinagre: "pon vino bueno en un vaso lleno sólo hasta la mitad y déjalo sin tapar... Si quieres hacerlo más rápidamente, calienta un metal o una piedra y ponla en el vino, sin tapar la boca del vaso. $\mathrm{O}$ bien déjese el vaso al sol durante dos o tres días" (p. 177).

${ }^{22} \mathrm{Pp}$. 289-293. Por sus poderes contra la lujuria, "las mujeres romanas acostumbraban a llevar consigo los frutos del agnocasto en los funerales, cuando por motivos de pública dignidad era preciso guardar continencia".

${ }^{23} \mathrm{P}$. 371. Además, la amatista "es parecida al alumbre por sus propiedades de resistencia a los maleficios de los magos".
} 
y la misericordia "seca los apostemas y hace desaparecer de ellos el color de la ictericia, gracias al buen corazón y a las limosnas piadosas". La planta es buena contra la picadura de escorpión, y la misericordia "se opone a la tiranía del hombre malvado que no respeta al pobre"24.

La caridad está simbolizada en el diamante con el que comparte numerosas cualidades: el diamante no cede al hierro ni a otras materias y la caridad de los mártires nunca cedió ante la rabia de los tiranos; el diamante es la piedra de la reconciliación ${ }^{25}$ y a la reconciliación mueve la caridad; así como el diamante sólo se rompe si derramamos sobre él "sangre reciente y caliente de chivo", la caridad sólo cede al amor de Cristo, y por ser la más valiosa de las virtudes, es comparable la caridad al áurea alejandrina, "el mejor de todos los electuarios"

La. paciencia tiene su equivalente físico en la almártaga, piedra que refrena la ira y calma el ánimo. De valor curativo universal es el agárico, especie de hongo que "crece al pie de las raíces del abeto", y de la misma forma que el agárico cura casi todas las enfermedades, la piedad socorre todas las miserias o, actuando como el ámbar -que fortalece el corazón y alivia la sofocación de la matriz- "la piedad levanta y conforta al pobre y al necesitado, al debilitado y al sofocado y los eleva y exalta para que se sienten en el trono de los príncipes en la gloria celestial"26.

Una de las manifestaciones del aire, el viento Aquilón, representa la malicia mientras el viento del desierto es comparable a la soberbia. El Aquilón "reseca el aire, congela el agua, produce esterilidad en la tierra y tempestades en el mar" y la malicia "reseca las lágrimas de la compasión,

\footnotetext{
${ }^{24} \mathrm{Pp}$. 173-175. La injusticia social es un tema recurrente en la obra de Juan Gil, que dedica el capítulo séptimo de la Historia de Zamora, a narrar "las infidelidades de los poderosos sobre todo y quiénes originaron desde el principio traiciones, revueltas y saqueos"; En el tratado noveno de la Historia de España recuerda que los poderosos serán juzgados duramente porque "quienes debieron regir dignamente todo el mundo, todo el mundo destruyeron miserablemente, como se verá por los ejemplos que siguen" (De preconiis Hispanie, p. 167) y en las páginas dedicadas al rey avaro, le ordena "que no oprima a los pobres, viudas, huérfanos y súbditos con impuestos desacostumbrados..." (p. 57).

${ }^{25}$ P. 1491. Según Dioscórides, "si la mujer se hubiera apartado del marido, el poder del diamante hace más fácil el retorno de la mujer a su perdón... Si con la debida precaución se coloca un diamante auténtico junto a la cabeza de la esposa dormida, su marido podrá saber si le es fiel; pues, si es fiel, la fuerza del diamante la empuja a abrazar al marido; en cambio, si no lo es, la fuerza del diamante la aparta de él y, como si fuera ya indigna de la presencia del diamante, cae de la cama" (p. 233).

${ }^{26}$ Pueden verse las comparaciones en las pp. 267 y 375 . El poder curativo del agárico se extiende a la epilepsia, el asma, la úlcera de pulmón, la ictericia, el dolor de estómago y de hígado, las flemas; provoca la orina y calma el dolor de riñones, las fístulas y hemorroides..
} 
enfría la llama del amor, retarda y debilita la fuerza en el trabajo y ahoga, porque produce miedo y desesperación". La soberbia es como el viento del desierto que destruyó la casa de Job y dio muerte a sus hijos; con ella se derrumba la casa, el "alma del pecador", cuando el viento del desierto, "la sugestión del diablo", golpea las cuatro esquinas de la casa que no son sino "la piedad, la caridad, la justicia y la prudencia", y al secarse éstas, cae el edificio sobre los hijos de Job, "y los hijos de Dios, que mediante la gracia tenían la vida y la libertad, por culpa de la soberbia incurren en una muerte espiritual y pierden la libertad de la justicia"27.

La temida calvicie o alopecia se compara a la indiscreción de la mente porque "así como el pelo de la cabeza simboliza la discreción de la mente, así la caída del pelo representa la indiscreción. Y lo mismo que la cabeza pierde toda su belleza cuando empieza a perder la cabellera, así también desaparece todo el ornato de las virtudes cuando la mente pierde la discreción", como sin duda podría atestiguar Sansón, privado de su fuerza, al perder el cabello "por culpa de la navaja de la astucia femenina"28.

La avaricia tiene su símbolo en el alga marina; ésta ata y enfría los pies de los nadadores y los ahoga, y la avaricia "torna a los hombres fríos, falsos, intransigentes e insaciables porque, cuanto más poderosos son, más agua quieren... El avaro jamás tiene bastante dinero"29.

La opresión de los débiles está simbolizada en el azor, al que son comparables quienes "parecen mansos e inofensivos exteriormente y sin embargo se dedican a robar, como los ladrones y como los poderosos, en secreto", y de manera más directa personifica a los opresores de los débiles

\footnotetext{
${ }^{27}$ Pp. 258-259.

${ }^{28} \mathrm{Pp}$. 361-363. En la obra de Juan Gil no faltan recetas contra la calvicie, como la que reproducimos a continuación: "Se diluye dragacanto blanco y goma arábiga en agua de rosas; se mezcla con igual cantiduad de ungüento y se unta la cara del enfermo, permaneciendo toda la noche con la cara envuelta en un paño; por la mañana se lava la cara y se limpia con leche de semillas frías o con leche de cabra o con el vino donde haya cocido una serpiente - se dice que el vino gusta mucho a las serpientes-" (p. 361).

${ }^{29} \mathrm{P}$. 305. Juan Gil ha desarrollado ampliamente el tema en el De preconiis, donde puede leerse: "Todo lo demás tiene fin, la avaricia no lo conoce. La Tierra tiene sus límites y el agua está limitada así como el aire o el cielo; sólo la avaricia carece de medida. Si se le da la tierra, pide el mar; si el mar, pide el aire; si el aire, desea el cielo; si el cielo, quiere igualarse a Dios; si puede igualarse a Dios quiere estar sobre él... Esta es la avaricia, por la cual se pierden los reyes, corren hacia la mentira, rompen los pactos, pierden la amistad, cambian los reinos, se producen los naufragios..." (p. 56).
} 
uno de los tipos de azor, el mochuelo, pájaro de escasa potencia física, cuyas presas "son aves pequeñas" 30 .

Los hombres vanos e hipócritas están representados por el auricalco, metal de bronce o cobre cuya superficie brilla como el oro y engaña como engañan los sofistas que, "a causa de la palabrería parecen poseer la verdad de la ciencia", o los hipócritas, que "parecen nobles y sinceros gracias a la simulación exterior de honestidad y están blancos por fuera, pero por dentro están podridos" ${ }^{13}$. Los malos médicos, los jueces y los abogados mentirosos tienen su símbolo en el oropimente: éste depila los cabellos y aquéllos "despellejan a los pobres"32.

El continente misterioso, África, abrasado por el sol y habitado por animales y hombres horrendos, es comparable al mundo, "hervidero de múltiples ambiciones" y habitado por hombres malvados comparables a las bestias porque no comprenden que son superiores a ellas $^{33}$. Albania, en cambio está habitada por hombres albinos "con ojos coloreados y glaucos en la pupila, de tal manera que ven mejor de noche que de día", símbolo de los hombres de gran prudencia y discreción, que "preven con mucho tiempo la adversidad y la prosperidad" ${ }^{13}$.

El amplio estudio sobre los bostezos finaliza con la comparación entre los bostezos y estiramientos y las pasiones desordenadas del espíritu, que provocan "pensamientos, complacencias, consentimientos y actos diversos de carácter nocivo y ligero, las cuales a su vez, arrastran al hombre a la perdición de su cuerpo y de su espíritu y hacia el fuego eterno"35. Juan Gil se limita aquí a seguir las enseñanzas de Hipócrates, Galeno y Avicena y aunque incluye con Galeno el bostezo, la tos, el eructo, el estornudo, el

\footnotetext{
${ }^{30}$ Se dedican a los azores las pp. 181-227.

${ }^{31}$ Pp. 1492-1493.

${ }^{32} \mathrm{P}$. 1497. El oropimente o arsénico correctamente utilizado es un buen depilatorio cuyo poder aumenta cuando se cuece con cal viva. La fórmula de preparación es la siguiente: "coge cuatro onzas de cal viva, disuélvelas en agua y ponla a hervir; luego añádele una onza de oropimente y ponlo a cocer. Estará perfectamente cocido cuando metas dentro una pluma y se depila prácticamente sola". Con esta mezcla se puede realizar la depilación, pero se recomienda hacerlo en un lugar caliente y tras aplicar el ungüento, "lavar con agua templada, porque si el agua es fría o muy caliente, te excoriaría la piel" (p. 1495).

Sobre la opresión de los pobres, v. lo indicado en la nota 24 y las líneas referidas al mochuelo (texto y nota 30 ).

${ }^{33}$ P. 259

${ }^{34}$ P. 299.

${ }^{35}$ P. 321
} 
estiramiento y el castañeteo de dientes en "una clase común, o sea, el movimiento malo", nada dice del bostezo como símbolo y anunciador de la muerte, aspecto al que se ha referido Juan Gil cuando, en otra de sus obras, habla de las Letanías con las que se pretendió combatir la gran peste que asoló Roma durante el pontificado de san Gregorio Magno: algunos "estornudaban frecuentemente y con los estornudos exhalaban el espíritu", y por esta razón "cuando se oía estornudar a alguien inmediatamente se decía Dios te ayude y de este hecho ha quedado la costumbre de que cuando alguien estornuda inmediatamente decimos: El Señor te ayude (Jesús)"36.

La envidia es como el azogue y como él separa, corroe y carcome todas las cosas; "el envidioso adelgaza cuando las cosas le van bien al vecino..., sufre y llora con la fortuna ajena, se alegra con sus fracasos y se felicita por las miserias ajenas..., la virtud le molesta, la felicidad lo hiere, la dicha lo humilla, la alegría lo atormenta"37.

\section{LOS DONES DEL ESPÍRITU Y SUS EQUIVALENCIAS}

Con el signo Aries del zodiaco se compara la gracia que recibe el alma cuando se arrepiente de sus pecados: cuando el sol está en Aries se produce el equinoccio, en el que noches y días son iguales, y el alma confortada por la gracia "se ve colmada de tantas satisfacciones como tribulaciones la afligieron, y la primitiva tristeza se torna en gozo"38. También los meses pueden tener sentido y valor simbólico, y abril, mes en el que se abren semillas y flores, simboliza el verdor de la gracia, que mueve al alma hacia el arrepentimiento y la devoción, y a engalanarse con

\footnotetext{
${ }^{36}$ Publica una traducción del texto latino J. L. MARTín, Juan Gil de Zamora: Maremagnum de escrituras, Dictaminis epithalamium, Libro de las personas ilustres, Formación del Príncipe, Zamora, 1995, pp. 39-42. Otro símbolo precursor de la muerte es el bostezo: "cuando alguno bostezaba varias veces moría al instante y por esto cuando alguien tenía ganas de bostezar se apresuraba a hacer la señal de la cruz sobre sí mismo, costumbre que ha quedado entre nosotros desde entonces".

${ }^{37}$ P. 1025. Para el envidioso no hay consuelo; su enfermedad es incurable, "un sufrimiento sin respiro, un suplicio ininterrumpido... es la peste que arrojó al ángel del cielo y al hombre del paraíso..., la peste que golpeó a los hijos de Israel en el desierto; la envidia armó contra José a sus hermanos, arrojó a Daniel al foso de los leones y fue la envidia, finalmente, quien clavó en la cruz a Cristo, cabeza nuestra". No de otra manera actúa el azogue o mercurio, cuyo humo destruye el oído y "hace que huela mal la boca cuando pasa por ella..., estropea la vista... es mortal a causa de su enorme poder corrosivo..." (p. 1025)

${ }^{38}$ P. 1033.
} 
las virtudes y con los buenos ejemplos a través de los cuales la luz de la conciencia alumbra a los hombres para que glorifiquen al Padre eterno ${ }^{39}$.

El ágata, la piedra de los reyes y los héroes, tiene propiedades similares a los del espíritu de profecía; si la primera ayuda a vencer los peligros, da fuerzas al cuerpo, hace al hombre "hermoso, atractivo, persuasivo, de buen color y de fácil palabra y lo protege contra los contratiempos", favorece la vista, elimina la sed y el veneno y despide olor agradable cuando se quema, el espíritu profético fortalece a quien lo posee en los peligros y contratiempos, lo hace" grato a los ángeles, le da visión clara de las Escrituras, le quita la ambición mundana "y con sus aromas y ungüentos los hace olorosos y de buena fama"40.

La verdad y el ácoro, raíz de una planta mencionada por Dioscórides, Galeno y Avicena, ofrecen numerosos paralelismos: el ácoro agudiza la vista y la verdad el entendimiento; el primero provoca la orina, y la verdad "vacía la sentina de la falsedad"; el ácoro evita que las abejas sean engañadas por el viento ${ }^{41}$, y la verdad de la fe evita que los creyentes "sean llevados al error por las vanas palabras de los herejes"; el ácoro aclara el color, y la verdad clarifica el entendimiento; el ácoro es bueno para el dolor de dientes y la verdad "calma el remordimiento de la conciencia o de la mente"; lo mismo que el ácoro es bueno para el dolor del hígado, del costado, del pecho y del vientre y para la dureza del hígado, "la verdad se opone al contagio y a la dureza de la maldad herética".

Las virtudes curativas de los "buenos pensamientos", que purgan el alma, están representadas por los asfódelos, nombre de una hierba que también se conoce como "el gamón, el albuco y el ciencabezas"; esta planta es buena para la calvicie, las úlceras y las magulladuras, la picadura de escorpión y mordedura de vívora, la hinchazón de los testículos y de las mamas y, sobre todo, para los ojos: con ella se elabora un colirio cuyos efectos permiten afirmar que "lo mismo que los asfódelos purgan el ojo,

\footnotetext{
${ }^{39}$ P. 827.

${ }^{40} \mathrm{Pp} .170-171$. Hay diversos tipos de ágata, cada uno con sus virtudes específicas: la negra se utiliza en las coronas de los reyes, y sirve para descubrir los sueños cuando se coloca "junto a la cabeza de una persona dormida"; el tipo cretense "infunde fuerzas al cuerpo y torna a uno hermoso y atractivo... La clase índica favorece la vista y actúa contra la sed y el veneno" y quien lleva un ágata consigo, "resultará muy atractivo, tal como se lee de Eneas, que llevaba un ágata en la vaina".

4I"Para que las abejas no escapen y no abandonen el enjambre, cuelga la hierba de Venus (el ácoro) en la colmena de las abejas y nunca las desorientará el viento" (p. 229).
} 
también los buenos pensamientos purgan el alma"42. La "buena conciencia" está representada o simbolizada por el aire al que Juan Gil dedica un amplio tratado en el que pueden verse reflexiones sobre las diversas estaciones del año y las características positivas y negativas o enfermedades que cada una conlleva ${ }^{43}$. Como el aire, la buena conciencia tiene la virtud de "hacer algo menos denso, más sutil y más ligero y de elevarlo hacia lo alto"; uno y otra se hacen más densos y oscuros en contacto con los humos y vapores de la tierra o cuando se le adhieren "las vanidades del mundo"; y de la misma manera que el aire puede generar calma o tormentas, enfermedades o buena salud, "la buena conciencia genera virtudes, la mala en cambio es causa de muchos vicios".

\section{EL HOMBRE Y SUS MUNDOS}

Con el árbol es comparable el hombre: la raíz es el símbolo de la cabeza con el pelo; el tronco es el cuello; las ramas los pies y las manos; las hojas los dedos. La actividad del hombre tiene gran similitud con las operaciones de los árboles, según puede apreciar "el sabio por si sólo (y) en su correspondiente lugar hablaremos de cada una de ellas"44.

La organización jerárquica de la sociedad humana está determinada por la de los ángeles para cuyo estudio en profundidad remite Juan Gil al amplio tratado que dedicó a los ángeles en su obra Armario de las Escritu$\mathrm{ras}^{45}$ de la que aquí ofrece un resumen. En el capítulo dedicado a las tres jerarquías, menciona Juan Gil "una jerarquía triple según los tres tipos de cosas sagradas y racionales, es decir, de personas divinas, de ángeles y de hombres". En la primera o jerarquía suprema (la Trinidad), el orden no viene fijado por el mando sino por el origen; la segunda o jerarquía celeste

\footnotetext{
${ }^{42} \mathrm{La}$ fórmula del colirio es fácil de realizar: "Toma media onza de azafrán y una onza de mirra, ponlos a hervir en media libra de vino tinto bueno y en una libra de asfódelos hasta que se evapone de nuevo la mitad, exponlo al sol durante bastantes días hasta que se evapore la mitad, y guárdalo en un vaso de bronce; si te dan en los ojos este colirio, constatarás su gran eficacia" (p. 263)

${ }^{43}$ Puede verse el texto en las pp. 237-259.

${ }^{44}$ Dedica a los árboles las pp. 951-1009, pero en ellas no se encuentra ninguna otra consideración aplicable a la sociedad humana.

${ }^{45}$ Sobre esta y otras obras de Juan Gil, v. las páginas escritas por José-Luis MarTín y Jenaro Costas, De preconiis Hispanie o Educación del Príncipe, Zamora 1996.
} 
es la formada por los ángeles y es triple a su vez: epifanía la categoría superior, hiperfanía la del medio e hipofanía la inferior. En la primera se incluyen serafines - cuyo don más importante es la caridad-, querubines - ciencia o conocimiento de Dios- y tronos - don de juicio-; en la segunda principados - don de la reverencia-, dominaciones - don del dominio - y potestades - cuya virtud fundamental es "alejar las adversidades"-; y en la tercera jerarquía, virtudes - "cuidado de las leyes naturales"-, arcángeles y ángeles, que tienen como atributo común la revelación de los secretos divinos, misión que se encomienda a unos o a otros según la importancia del secreto.

A imitación de estas jerarquías se organiza la sociedad humana: entre los servidores del rey hay algunos muy próximos al monarca como son los consejeros, ministros y encargados de cámara (primera jerarquía de ángeles "que se encargan de la asistencia directa de Dios y están siempre pendientes de él" y se caracterizan "por un amor inmenso..., un conocimiento perfecto... y una perpetua comprensión y fruición de Dios"); otros se cuidan de los asuntos de gobierno del reino en general como los jefes del ejército o los administradores de la justicia (segunda jerarquía, que tiene "como función y razón de ser el cuidado y gobierno de los hombres en general", función que se desdobla en tres: "presidir y mandar..., ejecutar las órdenes... (y) apartar los obstáculos e impedimentos)", y otros están al frente de una región o parte del reino como regidores, gobernadores y cargos de menor importancia (tercera jerarquía, en la que se distingue entre quien realiza funciones similares a las de los gobernadores persas, quien gobierna una colectividad o quienes, como los ángeles, están "al cargo de una persona (concreta") ${ }^{46}$.

La conexión entre el mundo terrenal y el celestial se organiza a través de la Iglesia, comparable a la península de Acaya. La Iglesia es "como una isla de este mundo, rodeada del gran oleaje del mar, es decir, envuelta en tribulaciones, por sus méritos elevadísima, muy defendida por las virtudes y fundada por el Hijo del sumo rey", como Acaya, que es casi toda ella una isla cuya capital "es Corinto, lugar muy estratégico... ya que es casi imposible el acceso a ella debido a la altura del lugar, a la multitud

${ }^{46}$ Pp. $453-469$. 
de gente que la habita, a su situación estratégica y a la cercanía de la ciudad al mar. Fue fundada por Corinto, hijo de Orestes" ${ }^{47}$.

No menos justificadamente representan a la Iglesia las amazonas descritas por san Isidoro: son las "esposas de los godos... que, al haber sido asesinados a traición sus maridos... empuñaron las armas de ellos y se tomaron la correspondiente venganza... y decidieron vivir en adelante sin el consorcio de los varones". Cuando la Iglesia se sustrae a los placeres mundanos actúa como las esposas que se alejan del marido, como las amazonas que viven lejos de los hombres; es "como si se cortara los pechos de los placeres carnales", y del mismo modo que la amazona toma las armas del marido, la Iglesia toma las armas de Cristo y lo venga cuando ataca al ejército de los vicios ${ }^{48}$.

Los servidores de la Iglesia, el estado religioso, "que llama a la orden a los niños cuando aún tienen pocos años, luego los seca con el ayuno y los endereza con la disciplina y, finalmente, los conforta dentro de la religión para que reprendan y repriman, primero en sí mismos y luego en los otros, el flujo de los deleites carnales y el flujo o apetito de las cosas mundanas", tiene su comparación en la acacia o jugo de las ciruelas verdes cuyo proceso de elaboración es el siguiente: "se recogen las ciruelas antes de su maduración, se les extrae el jugo y se deja secar al sol... Tiene la cualidad de costreñir y confortar"49.

\section{EL MUNDO FÍSICO Y DIOS; LOS SANTOS Y SU PREFIGURACIÓN}

El abismo, "la profundidad impenetrable de las aguas", es un símbolo múltiple: Es "oscuro, profundo, capaz de recibir todas las aguas y fluidos, insaciable... inescrutable, inagotable, comunicable"; impenetrable como Dios, oscuro como el infierno o el pecador, insaciable como el avaro, comunicable como la bondad y la piedad divinas. Abismo es llamado Cristo por tres razones: de él salen todas las aguas y Él es el principio de todo bien; sus profundidades son inagotables y Su mediación nunca falla; al

\footnotetext{
${ }^{47} \mathrm{Pp} .171-173$

${ }^{48} \mathrm{Pp} .371-373$

${ }^{49}$ Pp. $165-166$.
} 
abismo vuelven todos los ríos y Cristo es complemento de todas las buenas obras.

Al abismo puede ser comparado, también, el apóstol Santo Tomás porque si en el primero hay oscuridad y profundidad y está en continuo movimiento, el apóstol tuvo la oscuridad de la duda, la profundidad del reconocimiento de la resurrección de Cristo y continuidad en la predicación de la fe. "El abismo Cristo, principio de todas las buenas obras, llamó hacia sí al abismo Tomás (a todos los creyentes podríamos leer aunque no esté escrito) para que lo reconociera. El abismo Cristo, medio indefectible, llamó a santo Tomás para que lo imitara. El abismo Cristo, fin y complemento de las buenas obras, llamó al abismo Tomás para que se pareciera a él en la gloria eterna; para que de esta manera pasara de la oscuridad a la luz, de la luz al mérito y del mérito al premio"50.

Cristo está simbolizado igualmente en el alumbre blanco "porque fue engendrado en el vientre virginal de la sangre purísima de la Virgen, y, lo mismo que el alumbre, es una medicina universal, que cura a los que se duelen de corazón y cicatriza sus heridas"51.

Si Cristo es el Abismo y, como veremos más adelante, el viento Austro, el Espíritu Santo tiene como símbolo físico la grasa, ya que "une y unge, alegra e inflama, conforta y conforma... limpia los afectos del corazón para que ame con dulzura, limpia la razón del alma para que ame sabiamente, conforta el poder de la mente para que ame con fuerza... ablanda los corazones duros; a los hinchados, es decir, a los soberbios, los humilla y los torna más aceptables ante Dios" ${ }^{52}$. Puede compararse el Espíritu al signo de Acuario, al que se representa derramando agua sobre sus manos, símbolo de la gracia que el Espíritu concede. Puede igualmente compararse su gracia a la brisa, que refresca a los acalorados y da calor a quienes tienen frío ${ }^{53}$.

\footnotetext{
${ }^{50} \mathrm{La}$ descripción del abismo físico ocupa un espacio siete veces inferior al destinado a los “abismos" espiriturales o morales (Id. pp. 147-165)

${ }^{51}$ P. 369. Mezclado con agua mata los chinches y piojos y elimina el mal olor de la boca; mezclado con heces de vino cura el herpex; con sal, cura las úlceras, y el mal olor de axilas e ingle si se le añade agalla; y puede curarse la sarna con este preparado: "Coge azufre vivo, litargirio y alumbre, o quita, si te parece el azufre, y ponlo todo a hervir en vinagre y aceite de nueces y unta al enfermo para el baño; lava la parte afectada con agua caliente y luego úntala. El baño de agua aluminosa es muy saludable para los hidrópicos, los sarnosos y los gotosos".

${ }^{52} \mathrm{P} .235$

${ }^{53} \mathrm{Pp} .927$ y 1489.
} 
Entre Dios y el hombre se encuentra la Virgen, que tiene su símbolo en el aire y como él se convierte en lluvia o la dispersa a su paso. La Virgen es lluvia cuando "nos es propicia por su benignidad", y la lluvia "se dispersa cuando su clemencia se retrasa a causa de nuestra maldad". Como el aire, la Virgen produce múltiples beneficios: si el primero es vivienda de las aves, respiración de los animales y gracias a él se riegan y crecen las cosas que nacen de la tierra, la Virgen nos "conforta en las tribulaciones, nos escucha en las oraciones y fecunda nuestro trabajo"54. La aurora, el alba o amanecer, son también símbolos de la Virgen pues una y otra significan "plenitud de la luz"55, y la Virgen es "fuente sellada de sabiduría..., huerto cerrado, donde brillan los rosales de más hermoso colorido...; huerto al que no afectan los cambios de viento... Huerto cerrado, pero no con muros de cemento y piedras durísimas, sino rodeado por un regimiento de ángeles... Fuente de donde se surten de modo natural todas las demás fuentes que riegan , empapan e inundan la superficie de la tierra... Fuente sellada efectivamente con el sello de la Trinidad, a fin de que el ladrón maligno no se atreva... ni a tocarla siquiera. En este huerto las semillas muertas vuelven a germinar... En esta fuente se oculta la gran variedad de los sacramentos..." 56 .

El tratado sobre el agua ${ }^{57}$ incluye un capítulo sobre Consideraciones morales adecuadas al agua en el que se recuerda que para poseer las aguas espirituales se ha de acudir a la Virgen de acuerdo con el texto del capítulo veinte del libro de los Números: "habladle a la roca y la propia roca os dará agua". La roca es la Virgen y al agua son comparables los beneficios y gracias espirituales que se obtienen por su mediación si se le reza, si se le habla pues hablar es orar, y del mismo modo que para hablar bien se precisan "agilidad en los labios, continuidad en los dientes, flexibilidad en

\footnotetext{
${ }^{54} \mathrm{El}$ Apocalipsis prefigura la imagen de la Virgen cuando dice que "El ángel derramó su copa en el aire y salió una voz del trono diciendo: está hecho. Y se produjeron rayos, voces y truenos y un terremoto grande". El ángel derrama su copa en el aire cuando ofrece a la Virgen nuestras súplicas; el está hecho se oye cuando las súplicas son atendidas y el aparato que acompaña a esta decisión tiene como no podía ser menos una fuerte carga simbólica: "los rayos iluminan y serenan nuestras tribulaciones"; los truenos alejan las tentaciones de la Serpiente; las voces y pregones anuncian "nuestras acciones de gracias", y los terremotos son buenos augurios por los actos virtuosos, de la misma manera que los vicios dispersan las súplicas de la Virgen en nuestro favor (p. 257).

${ }^{55}$ P. 1527

${ }^{56} \mathrm{P} .1551$

${ }^{57}$ P. 847-925.
} 
la lengua y salud en la garganta y los pulmones", la oración eficaz ha de estar acompañada de la salud de la penitencia -"limpieza de los pecados"-, la flexibilidad de la obediencia -"ejecución de los mandamientos"-, la unidad de la caridad -"amor al prójimo"- y la agilidad de la piedad -"socorrer a los desgraciados y eliminar los lujos superfluos"-.

El amplio capítulo dedicado al azor ${ }^{58}$ se inicia comparando al ave con los hombres, "que parecen mansos e inofensivos exteriormente y sin embargo se dedican a robar, como los ladrones y como los poderosos, en secreto", y finaliza con una "puclra comparación" entre el azor y San Francisco de Asís, cuyo punto de partida es el versículo del Libro de Job: "Gracias a tu sabiduría, oh Dios, se empluma el azor extendiendo sus alas al Austro". Leído el versículo con los ojos del cuerpo, se refiere al cambio de plumas del azor, pero si se realiza una lectura espiritual, puede referirse "a la impresión de las llagas de nuestro santísimo padre Francisco, cuando, transformado su aspecto en el de un serafín, recibió en su cuerpo la marca de los sagrados estigmas".

La vida del azor y la del fundador de los franciscanos permite mantener la comparación: el ave retira la comida a sus hijos cuando llega el momento de abandonar el nido y los echa de él; con su propia hiel elimina la niebla de sus ojos; ataca a sus presas con el pico, las garras y el pecho; le gusta la carne fresca y ensangrentada; y San Francisco fue severo con sus hermanos y para ellos instituyó una orden severa, cuya regla actúa como medicina; cual ave de presa se apoderó de los hombres y los convirtió con su predicación; le apetecía la carne fresca y lamía la sangre al meditar continuamente en la Pasión de Cristo ${ }^{59}$.

La comparación con el azor no es gratuita; sirve al franciscano para explicar, no sin forzar los textos, la supervivencia de la Orden, la tolerancia que hacia ella tuvo la jerarquía eclesiástica, "condenada" según Juan Gil, a respetar a san Francisco en cumplimiento de la prohibición de Yavé al

\footnotetext{
${ }^{58} \mathrm{Pp}$. 181-227. Juan Gil ofrece en las páginas iniciales un índice completo de los temas que estudiará: analiza el nombre, las diferentes clases' de azor, la complexión y disposición de sus cuerpos, la nidificación y educación de los pollos, la domesticación, ceba y adiestramiento para la caza, la agudeza visual, la confección de medicinas con los cuerpos de los azores, las enfermedades de estas aves y su muerte, para añadir un décimo apartado en el que desarrolla "una comparación de San Francisco con el azor" (pp. 182-183).

${ }^{59}$ Id. , p. 219
} 
pueblo de Israel de comer determinadas aves, entre ellas el azor ${ }^{60}$. De paso, el texto bíblico permite extender la comparación al águila, el grifo y el buitre: "el águila enseña a sus hijos a lamer la sangre, el azor es un buen cazador, el buitre tiene un olfato prodigioso, el grifo lleva una piedra preciosa muy eficaz contra los animales venenosos", y el santo fundador de la Orden "enseña a lamer la sangre de la divina pasión..., enseña el arte de la caza mediante la predicación", como el "buitre de fino olfato" fundó una orden para captar el olor de la patria celeste, y, como el grifo, lleva consigo "la piedra preciosa de la virtud contra el veneno de la astucia del diablo".

Como azor, san Francisco extiende sus alas hacia el viento Austro, que es a su vez símbolo de Cristo clavado en la cruz. El Austro es un viento cálido, húmedo, poderoso y florido como Cristo: cálido por la fuerza del amor, húmedo por la efusión de su sangre, poderoso al soportar el dolor y florido al restaurar nuestro honor, y en reconocimiento de estas cualidades del Austro-Cristo el creyente le debe "amor, ya que él nos amó..., veneración, ya que él enriqueció a la Iglesia..., soportar el dolor que él mismo soportó..., reverencia, porque él nos redimió"61.

Hacia este Austro extiende el azor-san Francisco sus alas, sus sentimientos, y de la misma forma que el azor mueve las alas en todas direcciones, el fundador de los frailes menores mira "hacia arriba para contemplar los premios de los bienaventurados y para desear la divinidad de Cristo...; hacia abajo para no olvidar los suplicios de los condenados y la debilidad de la humanidad de Cristo...; hacia la derecha para imitar los ejemplos de los santos y la rectitud de vida...; hacia la izquierda para evitar los malos efectos de los pecados y la amargura de la muerte"62.

Mirando al austro cambia sus plumas el azor, y mirando a Cristo recibió el santo de Asís sus plumas, los estigmas de la pasión de Cristo. Las

\footnotetext{
${ }^{60}$ Deuteronomio, 14, 11-14. "En virtud de todo esto, queriendo Dios que san Francisco y sus hijos no fueran destruidos por la jerarquía eclesiástica ni comidos ni aniquilados, sino más bien que fueran apreciados y favorecidos, por eso dice el capítulo catorce del Deuteronomio: Éstas son las aves, es decir, los religiosos preocupados sólo por las cosas del espíritu, que no debéis comer, a saber, el águila..." (p. 219).

${ }^{61}$ Una vez más se utilizan textos bíblicos en apoyo de la comparación: "La esposa" en el Cantar de los Cantares... "gemía y suspiraba por este viento, austral, tan beneficioso y virtuoso, cuando decía, levántate, Aquilón, ven Austro, sopla sobre mi huerto y volarán por el aire sus aromas". Lógicamente, el Aquilón simboliza "la ira y la enemistad entre Dios y el hombre a causa del pecado, que corta el río de gracia y de gloria que fluye hacia nosotros" (p. 221).

${ }^{62}(I d .$, p. 221).
} 
plumas dan al azor belleza en su figura, rapidez de vuelo, variedad en su ropaje y un cierto parecido con el avestruz, y los estigmas hacen a san Francisco más resplandeciente en sus virtudes y obras, lo elevan por encima de todas las miradas, hacen más ardiente su amor y le dan una figura más parecida a la de Cristo, simbolizado ahora por el avestruz, "que tiene cuerpo de animal y alas de pájaro y es, por tanto, símbolo de Cristo, que posee la divinidad dentro de su humanidad".

El Éxodo viene una vez más en apoyo de otra nueva comparación simbólica buscada por Juan Gil: la concesión de los estigmas de la pasión está prefigurada en las palabras con las que Dios ordenó a Moisés fabricar un "tabernáculo de jacinto y de púrpura, de lino retorcido y de escarlata teñida dos veces". Los colores del velo significan los privilegios que consigo llevan los estigmas: "el lino retorcido significa una obra resplandeciente de santidad, ya que es una especie de lino blanquísimo. El jacinto significa una mente que destaca por el profundo conocimiento de la verdad, ya que es una gema muy parecida al color del cielo. La escarlata teñida dos veces simboliza un espíritu que posee el brillo de la doble caridad. La púrpura teñida de sangre simboliza la carne que palidece a causa de las heridas"63, y así, podemos concluir con Juan Gil, "San Francisco se asemejaba espiritualmente al azor, porque se había despojado de las plumas viejas y se había adornado con los estigmas nuevos".

En estos simbolismos y prefiguraciones bíblicas, san Francisco está acompañado por san Antonio; son los querubines de oro purísimo "que extendían sus alas y velaban el propiciatorio y se miraban mutuamente", construidos por Besalel, que no es otro que Cristo. San Francisco y san Antonio brillan, como los querubines, por su profundo conocimiento; el amor los torna rojizos, del color del oro; extienden sus alas en todas las direcciones y mientras velan el propiciatorio se adhieren a Cristo; se miran el uno al otro "observándose en mutua imitación"64.

De todos es conocido el simbolismo entre el cordero y Cristo pero quizá no el paralelismo que puede establecerse entre San Clemente y el cordero "que estaba en la cima del monte", según el capítulo catorce del

\footnotetext{
${ }^{63}$ Juan Gil reproduce a continuación el texto de San Buenaventura sobre la impresión de las llagas de Cristo en san Francisco (pp. 223-225).

${ }^{64}$ P. 221. San Antonio (de Lisboa) es incluido por Juan Gil entre los santos hispanos y de él dice que "fue el primer sucesor del padre Francisco en la Orden de los Frailes Menores y, en vida, mereció ver la cara de Jesús" (Preconiis, p. 105).
} 
Apocalipsis. El papa san Clemente, cordero por su santidad y perfección, está en la cima "de la Iglesia por la dignidad de su cargo"; si el primero es animal inofensivo, sufrido, humilde y útil, San Clemente es tan inocente que vive sin ofender a nadie, tan sufrido que lo matan y no protesta; tan humilde que no abre la boca cuando lo capturan y sus milagros prueban su utilidad. El monte sobre el que está el cordero es símbolo claro de la Iglesia y si en el primero el agua es más pura y libre de contaminaciones, el aire más saludable y los frutos más sabrosos, la Iglesia posee la pureza de la doctrina, el poder curativo de la medicina sacramental, la serenidad de la conciencia y la dulzura de la gracia ${ }^{65}$, y a este monte-iglesia alude el libro de los Números cuando afirma "que los hijos de Israel salieron de los sepulcros de la concupiscencia... llegaron al monte Galaad y luego se dirigieron al monte Ebrón". Los hijos de Israel son los cristianos que salen de los sepulcros del "paganismo y del judaísmo" y se dirigen al monte Galaad, a la cumbre de la Iglesia y luego al monte Ebrón, "la patria feliz..., la felicidad de la gloria"; Galaad es el lugar donde firmaron la paz Jacob y Labam y al que se dirigían los mercaderes para realizar sus negocios, y la Iglesia es el monte del pasto y del reposo, de la salud y del restablecimiento, del pacto y la reconciliación, de los negocios lucrativos, "por la abundancia de los dones espirituales". En Ebrón están sepultados, según san Jerónimo, Adán, Abraham, Isaac y Jacob, símbolos de los arrepentidos y penitentes (Adán), de los prelados honrados (Abraham) de los activos y trabajadores (Jacob) y de las almas contemplativas y los predicadores (Isaac) ${ }^{66}$.

Con las abejas - a cuya organización nos hemos referido antes- se compara a santa Cecilia y a san Ambrosio. Las abejas hacen ruido con sus alas al contraerlas y extenderlas para volar y "santa Cecilia hacía ruido cuando gemía en la oración, extendía las alas cuando contemplaba al Señor, y luego las contraía cuando predicaba a los que la rodeaban". Las abejas se ayudan unas a otras en el trabajo, estimulan a las perezosas y son capaces de morir en defensa de su morada, y santa Cecilia "ayudó a los pobres con sus limosnas, despertó la fe en los no creyentes con la realización de milagros y dio su vida soportando el martirio".

\footnotetext{
${ }^{65} \mathrm{Pp} .277-279$.

66" Adán es el símbolo de lo terreno... el penitente que reconoce la fragilidad de la propia condición. Abraham... representa al prelado que se ocupa en las tareas de gobierno y atiende al bienestar de los súbditos. Jacob... simboliza al cristiano activo que suplanta la carne por la práctica de las buenas obras. Isaac... es símbolo del alma contemplativa..." (p. 281).
} 
La relación de las abejas con san Ambrosio data de su infancia: cuando todavía era pequeño, un enjambre de abejas entró en su boca para representar las virtudes que con el tiempo lo adornarían: la abeja es limpia y pura en su alimentación, es diligente en el trabajo, tiene una fina sensibilidad y es fecunda en el parto, y san Ambrosio "se mantuvo puro e incorruptible frente a los placeres de la carne, fue constante en sus buenas obras..., sagaz y comedido frente a la presunción; y su fecunda vida espiritual se opuso a la desesperación". Si la abeja es la más pequeña de las aves y su fruto encierra el inicio de la dulzura, según indica el Eclesiástico, San Ambrosio fue abeja "por su diligencia en obrar bien, fue pequeño por el poco aprecio que tenía de sí mismo, volaba con la ligereza que le confería su integridad y era dulce por la dulzura de su devoción y de su oración", y su doctrina tuvo propiedades similares a las de la miel: incisiva, calorífica, laxante y curativa "por la amenaza de los eternos suplicios..., porque recuerda los beneficios recibidos..., porque denuncia los pecados (y) sana y salva mediante la promesa del precio eterno" ${ }^{167}$.

Otro de los santos más conocidos en la Edad Media, san Martín, tiene su paralelismo en el arco iris; a la aparición y formación, forma y aspecto y propiedades operativas del arco iris corresponden las tres épocas de san Martín como soldado, como religioso y como prelado. "En su época de soldado, estuvo empapado de piedad" - como el arco en una nube de agua-, "se elevó a lo alto por su humildad y se mantuvo derecho por la fidelidad". La forma del arco es la de un espejo circular de multiple colorido, y san Martín, cuando fue religioso, tuvo la circularidad de la fortaleza y de la paciencia y la singularidad de la austeridad y la abstinencia. Refiriéndose a las propiedades del arco iris, afirma Juan Gil que suaviza el calor, da paso a la lluvia y anuncia el fruto de la paz, y san Martín, que fue

\footnotetext{
${ }^{67} \mathrm{Pp}$. 745-751. Juan Gil vuelve de nuevo sobre el mundo de las abejas en las páginas 829 847, que pueden ser leídas como un tratado de organización política; v. como muestra el siguiente párrafo: "Las abejas nombran sus propios reyes, organizan sus propios pueblos y, aunque están bajo el mando de un rey, son sin embaro libres. Al rey nuevo lo quieren con un afecto natural y lo protegen con todos sus medios y consideran un honor dar la vida por él. Muestran tal respeto hacia su rey que ninguna se atreve a salir de casa ni en busca de la comida antes que salga el rey y ejerza su derecho de volar primero... En el enjambre de las abejas, ninguna permanece ociosa: unas combaten en una especie de batalla campal contra otras abejas, otras cuidan la comida, otras se ocupan de prever las lluvias o vigilan por si alguien las ataca, otras fabrican cera con sustancias de las flores, otras hacen las casas... Y en trabajos tan dispares, ninguna se ve molestada por la actividad de las demás y ninguna roba la comida.." Los editores de la Historia Naturalis incluyen en la obra el Tratado sobre los Animales, en el que se amplían considerablemente las páginas dedicadas a las abejas (pp. 1721-1793).
} 
justo y recto en el gobierno de los súbditos y generoso benefactor de los necesitados, como otro arco iris "derramaba aguas de devoción y sabiduría, mitigaba el ardor de la pobreza y de la indigencia y llevaba la paz de la equidad y de la justicia", propiedades que lo pusieron en relación con Dios, con sus inferiores y con los ajenos: "a Dios lo amaba, a sus inferiores los gobernaba y a los pobres los amaba y necesitaba". El paralelismo del arco iris se extiende a Cristo: su formación significa la caridad de Cristo, pues está formado por los rayos del sol; su colorido simboliza la humildad de Cristo; su forma la piedad ${ }^{68}$.

San Juan Evangelista está prefigurado en el águila que cita el Libro de los Proverbios: "Es difícil el camino del águila en el cielo", donde "el águila simboliza el privilegio de Juan y el cielo es el símbolo del evangelio de Cristo". Como el ave, "Juan se remontó muy alto, cuando conoció los secretos arcanos del futuro; conservó su fuerza, cuando soportó el exilio y el martirio; conservó la juventud, cuando subió al cielo en cuerpo y alma". También el libro de Ezequiel prefigura al evangelista cuando habla de "un águila enorme, de grandes alas y largas patas, llena de plumas multicolores, fue a Líbano y cogió médula de cedro". Juan es el águila y como él debe ser el cristiano que aspira al cielo, símbolo del Evangelio de Cristo, que sacia y colma todos los deseos como indica el propio Juan en el Apocalipsis: "apareció una señal portentosa en el cielo, una mujer vestida con el sol y con la luna a sus pies y sobre su cabeza una corona de doce estrellas", donde la mujer "simboliza piedad, el vestido la belleza, el sol el calor, la luna humedad, la postración indica utilidad, la cabeza el final, la corona dignidad, el número doce simboliza perfección porque consta de dos números perfectos, esto es, dos senarios, y la estrella en fin, simboliza la incorruptibilidad"69.

La predicación del apóstol san Pablo está representada por la plata ${ }^{70}$ con la que comparte las propiedades curativas, corrosivas, purificadoras y confortantes: la predicación de Pablo "curaba a los arrepentidos, corroía a los malvados, tornaba más bellos a los aventajados y confortaba a los esforzados que avanzaban". La vida de Pablo tiene su simbolismo en el

\footnotetext{
${ }^{68} \mathrm{Pp} .1013-1017$.

${ }^{69}$ Pp. 927-939.

${ }^{70}$ También es símbolo del predicador que, como la plata, "ha de ser claro, de reconocida virtud, sólido en sus conocimientos doctrinales, sonoro por su buena fama... " (p. 1027).
} 
oro, el metal más puro, más bello, sólido y duradero y dúctil al mismo tiempo, como Pablo: "puro de cara a sí mismo, caritativo con el prójimo, sólido y paciente con sus enemigos y humilde y obediente con Dios"71.

El oro es también símbolo de otro apóstol, Santiago, prefigurado en el libro de Job: "hay un lugar cuyas piedras son zafiros y su polvo es oro", y oro fue la vida de Santiago que se mostró radiante y lleno de gracia en vida y tras su muerte: su sepulcro, "visitado por gentes procedentes del mundo entero", es un zafiro, por su múltiple utilidad y su polvo, los caminos de su vida, "son oro a causa de su santidad". El oro no se consume ni pierde peso en el fuego, no se rompe al trabajarlo, es el más valioso de los metales y "mezclado con la comida preserva de la lepra", virtudes que pueden contemplarse en Santiago: "mostró valentía y fortaleza al aguantar los azotes, humildad y obediencia al cumplir los preceptos, un amor increíble al prójimo y en su predicación fue como médico que devuelve la salud". El zafiro simboliza los milagros del apóstol: cura la fiebre, es bueno contra los venenos, eficaz contra la pérdida de vista, buen remedio contra las dolencias cardiacas, y Santiago "repara los daños anteriores de sus peregrinos, los preserva de los peligros posteriores, los purga de los pecados inmundos y les concede gracia suficiente"72.

Y para finalizar esta ya larga relación de comparaciones, símbolos y prefiguraciones, recordemos que los apóstoles Judas y Matías tienen su símbolo en los vientos Aquilón y Austro, citados en el Cantar de los Cantares: "Levántate Aquilón -Judas-, y ven, Austro -Matías-". Mientras el Aquilón es viento que provoca tormentas en el mar, enfría el agua y hace estéril la tierra, el Austro es viento cálido, poderoso y húmedo y san Matías fue "cálido por su amor al Señor..., poderoso por la mortificación de sí mismo..., húmedo por la compasión hacia el prójimo", y a él alude el Libro de Job cuando afirma que Dios "hace aparecer en el cielo a Arturo, a Orión, a las Hiades y los ocultos recovecos del Austro". Arturo, Orión y las Híades son constelaciones, numerosa la primera, luminosa la segunda y lluviosa la última; los recovecos del Austro son los campos de la tierra y constelaciones y campos son símbolos del último de los apóstoles: "numeroso... por las variadas formas de mortificación...; luminoso... por la

${ }^{71} \mathrm{P} .1029$.

${ }^{72}$ Pp. 1531-1535. 
gracia y el amor...; lluvioso... por su misericordia y su pasión...; fecundo... por la eficacia de sus buenas obras", comparables a las del Austro, cuya "humedad empapa el suelo para la germinación, su calor abre la tierra para que produzca el fruto y su fuerza limpia el aire", de la misma forma que el predicador, san Matías, "emborracha la tierra", los corazones humanos, los abre a la contrición y los limpia "mediante la confesión y la gracia"73 a través de las cuales el hombre se acerca a su Creador.

\section{RÉSUMÉ}

L'Historia Naturalis écrite par Juan Gil de Zamora à la fin du XIII ${ }^{\mathrm{e}}$ siècle nous permet de connaitre les relations entre le monde physique et le monde moral et religieux et d'aprofondir le symbolisme du monde physique.

\section{SUMMARY}

The Historia Naturalis written by Juan Gil de Zamora at the end of the XIIIth century permits to know the relationship betbeen the physical world and the moral ant religious one, and permits to deepen in the symbolism of physical world.

${ }^{73}$ P. 1539. 